\title{
Sentimental herding in Borsa Istanbul: informed versus uninformed
}

\section{Nihat Solakoglu \& Nazmi Demir}

To cite this article: M. Nihat Solakoglu \& Nazmi Demir (2014) Sentimental herding in Borsa Istanbul: informed versus uninformed, Applied Economics Letters, 21:14, 965-968, DOI: 10.1080/13504851.2014.902015

To link to this article: https://doi.org/10.1080/13504851.2014.902015

曲 Published online: 08 Apr 2014.

Submit your article to this journal $\pi$

Џlll Article views: 122

View Crossmark data \lceil

Citing articles: 4 View citing articles 


\title{
Sentimental herding in Borsa Istanbul: informed versus uninformed
}

\author{
M. Nihat Solakoglu* and Nazmi Demir \\ Banking and Finance Department, I.D. Bilkent University, 06800 Ankara, \\ Turkey
}

This study searches for sentimental herding in Borsa Istanbul (BIST) using a state-space model for two distinct groups of investors/traders. We expect to find no sentimental herding in BIST30 as the investors are closely following the market, given their access to maximum amount of information and high quality of guidance from the world-known intermediaries that reduce information asymmetries. However, as the SNM investors are mostly local investors with smaller assets and with higher level of information asymmetry, we expect to find evidence of sentimental herding. As expected, we find no evidence of herding by the BIST30 investors from 2000 to 2013. In contrast, our findings provide evidence that the SNM investors demonstrate sentimental herding persistently and independently from market fundamentals in three stages: evidence of herding in the first stage (2000-2004), a 4-year (2005-2008) no-herding calm period and finally a volatile adverse herding pattern (2009-2013) where fundamentals about the firm values became more important.

Keywords: herding; state-space model; cross-sectional volatility; emerging market

JEL Classification: C12; C31; G12; G14

\section{Introduction}

Herding may simply be defined as copying the behaviour of other investors intentionally (Bikchandani et al., 2001). In one group of studies, herding is defined as one group of investors following another group who are perceived to have more access to market information (Banerjee, 1992; Lakonishok et al., 1992). Other group of studies employs a 'market-wide' approach, using the cross-sectional dispersion of returns (Christie and Huang, 1995; Chang et al., 2000) or that of betas of assets (Hwang and Salmon, 2004).

This study tests to see if the investors of the firms listed in two indices - the BIST30, the informed, and the Second National Market (SNM), the uninformed, of the Borsa Istanbul (BIST) ${ }^{1}$ - behaved differently in the aftermath of the country's financial crisis in 2000. The BIST30 covers the largest 30 firms in Turkey, ${ }^{2}$ mostly with foreign portfolio investments that account for about $60 \%$ of traded shares, while the SNM covers small- to medium-sized firms and firms de-listed from the National Index. ${ }^{3} \mathrm{We}$

\footnotetext{
*Corresponding author. E-mail: nsolakoglu@bilkent.edu.tr

${ }^{1}$ Borsa Istanbul (BIST) is the new name for the İstanbul Stock Exchange (ISE), which was founded in 1986.

${ }^{2}$ Of the 510 billion TL of the BIST capitalized value, the BIST30 alone accounted for 64\%, in January 2014.

${ }^{3}$ For details on these two groups, see www.borsaistanbul.com
} 
expect to find evidence of herding by the SNM investors/ traders, given that they have much less access to market information, ${ }^{4}$ and, in contrast, no herding by the BIST30 investors/traders given their high quality of expertise and access to market information. The sample considered covers the financial crisis of 2000-2001 and the global crisis of 2007-2008 as well as a period of successful structural reforms and economic policies supported by the IMF, motivated by the EU and implemented by the strong majority government.

Different from earlier studies, this study utilizes crosssectional SD of systematic risk, rather than those of returns, in a state-space framework for two distinct groups of investors with different level of information asymmetries. The remainder of this article is organized as follows. In Section II, we present the data and the model. Section III presents the results, while conclusions are in Section IV.

\section{Data and Model}

The data used are obtained from Matriks Data Terminal. ${ }^{5}$ For missing financial data, we utilize the web page of the public disclosure platform. ${ }^{6}$ Table 1 presents descriptive statistics of firms listed under the BIST30 and the SNM.

Firms in the BIST30 are much larger in size, in terms of both market capitalization and publicly-owned

Table 1. Descriptive statistics

\begin{tabular}{|c|c|c|c|c|}
\hline & Average & $\mathrm{SD}$ & Minimum & Maximum \\
\hline \multicolumn{5}{|l|}{ BIST30 firms } \\
\hline Total assets ${ }^{\mathrm{a}}$ & 43009 & 64467 & 1267 & 175444 \\
\hline Market cap $^{\mathrm{a}}$ & 8987 & 10293 & 320 & 32928 \\
\hline $\begin{array}{l}\text { Per cent open to } \\
\text { public }\end{array}$ & 38 & 19 & 3 & 86 \\
\hline $\begin{array}{l}\text { Foreign investor } \\
\text { share } \% \mathrm{~b}\end{array}$ & 60 & 23 & 18 & 86 \\
\hline Beta & 0.90 & 0.11 & 0.57 & 1.13 \\
\hline \multicolumn{5}{|l|}{ Second national firms } \\
\hline Total assets $^{\mathrm{a}}$ & 315 & 593 & 9 & 2703 \\
\hline Market cap $^{\mathrm{a}}$ & 207 & 259 & 12 & 1018 \\
\hline $\begin{array}{l}\text { Per cent open to } \\
\text { public }\end{array}$ & 24 & 25 & 0.92 & 98 \\
\hline $\begin{array}{l}\text { Foreign investor } \\
\text { share } \% \mathrm{~b}\end{array}$ & 0.26 & 0.99 & 0.00 & 05.Haz \\
\hline Beta & 0.52 & 0.27 & -0.05 & 1.22 \\
\hline
\end{tabular}

Note: ${ }^{\mathrm{a}}$ In million TL; ${ }^{\mathrm{b}}$ Matriks. proportions, than those in the SNM. The proportion of traded shares held by foreign investors, mostly institutions, is around $60 \%$ (on average). The same share for the SNM index is only $0.26 \%$, the highest being around $5.06 \%$. Moreover, in 2012, the average holding period was 316 days for foreign investors and only 37 days for local investors, showing the differences in investment strategies (Bourse Trend Report, January 2013). ${ }^{7}$ Given the structure of the two groups of investors/traders, it is plausible to expect the BIST30 investors to optimize their portfolios based on economic and firm fundamentals, keeping long-term trends in mind, while for the SNM investors, the hypothesis is that it is their sentiment that guides them in their investment decisions rather than market fundamentals (Hwang and Salmon, 2004).

To extract sentimental herding empirically, we follow Hwang and Salmon (2004), where the parameter of herding $h_{m t}$ is assumed to be proportional to the deviations of the true beta $\left(\beta_{\text {imt }}\right)$ from the market unit beta as follows:

$$
\frac{E_{t}^{b}\left(\gamma_{i t}\right)}{E_{t}\left(\gamma_{m t}\right)}=\beta_{\mathrm{imt}}^{b}=\beta_{\mathrm{imt}}-h_{m t}\left(\beta_{\mathrm{imt}}-1\right)
$$

where $\beta_{i m t}^{b}, \beta_{i m t}, E_{t}^{b}\left(\gamma_{i t}\right)$ and $E_{t}\left(\gamma_{m t}\right)$ are respectively the biased beta, the true beta, the conditional expectation on the excess return of stock $i$ and the conditional expectation of the market excess return all at time $t$. If there is no herding in Equation 1, then $\beta_{\mathrm{imt}}^{b}=\beta_{\mathrm{imt}}$. The cross-sectional variation of $\beta^{b}{ }_{\text {imt }}$ with $\log$ transformation becomes:

$$
\ln \left[\operatorname{Std}_{c}\left(\beta_{i m t}^{b}\right)\right]=\ln \left[\operatorname{Std}_{c}\left(\beta_{i m t}\right)\right]+\ln \left(1-h_{m t}\right)
$$

Rewriting Equation 2 in state-space format:

$$
\ln \left[\operatorname{Std}_{c}\left(\beta_{i m t}^{b}\right)\right]=\mu_{m}+H_{m t}
$$

where $\mu_{m}$ is aconstant in the short run and $H_{m t}=\ln$ $\left(1-h_{m t}\right) . H_{m t}$ is allowed to follow an $\operatorname{AR}(1)$ process. With exogenous variables for a test of robustness, e.g. return volatility $\sigma_{m t}$ and return $\gamma_{m t}$, the system becomes:

$$
\begin{aligned}
\ln \left[\operatorname{Std}_{c}\left(\beta_{i m t}^{b}\right)\right] & =\mu_{m}+H_{m t}+\theta_{c 1} \sigma_{m t}+\theta_{c 2} \gamma_{m t}+v_{m t} \\
H_{m t} & =\varphi_{m} H_{m t-1}+\eta_{m t}
\end{aligned}
$$

where $v_{m} \sim \operatorname{iid}\left(0, \sigma_{m v}^{2}\right)$ and $\eta_{m t} \sim \operatorname{iid}\left(0, \sigma_{m \eta}^{2}\right)$. When the variance and $\varphi_{m}$ are significant, with $\left|\varphi_{m}\right| \leq 1$, we conclude that there is herding with an $\mathrm{AR}(1)$ process.

\footnotetext{
${ }^{4}$ Wermer (1999), differentiating by size, states that herding in small, growth stocks is more likely.

${ }^{5}$ Matriks Information Distribution Services is a company that specializes in providing real-time financial data.

${ }^{6}$ www.kap.gov.tr

${ }^{7}$ www.tuyid.org/tr/
} 
Table 2. Kalman filter results of the state-space model, BIST30 and SNM

\begin{tabular}{|c|c|c|c|c|}
\hline \multirow[b]{3}{*}{ Variable } & \multicolumn{2}{|l|}{ BIST30 } & \multicolumn{2}{|l|}{ SNM } \\
\hline & $\begin{array}{l}\text { Base } \\
\text { model }\end{array}$ & $\begin{array}{l}\text { With } \\
\text { control } \\
\text { variables } \\
\text { Fstimate }\end{array}$ & $\begin{array}{l}\text { Base } \\
\text { model }\end{array}$ & $\begin{array}{l}\text { With } \\
\text { control } \\
\text { variables } \\
\text { Fstimate }\end{array}$ \\
\hline & Estimates & Estimate & Estimates & \\
\hline$\mu_{m}$ & $-0.441 * *$ & $-0.333 * *$ & $-0.315 * *$ & $-0.116^{* *}$ \\
\hline$\varphi_{m}$ & $0.650 * *$ & 0.260 & $0.939 * *$ & $0.959 * *$ \\
\hline$\sigma_{m v}$ & $0.093 * *$ & 0.892 & $0.147 * *$ & $0.140 * *$ \\
\hline$\sigma_{m \eta}$ & $0.043 * *$ & $0.092 * *$ & $0.035 * *$ & $0.016^{* *}$ \\
\hline $\begin{array}{l}\text { Market } \\
\text { volatility }\end{array}$ & $-11.284^{* *}$ & & $-22.064 * *$ & \\
\hline Market returns & $7.594 * *$ & & 3.872 & \\
\hline$\sigma_{m \eta / \mathrm{SD}} \ln \beta \ldots \ldots$ & 0.195 & & & \\
\hline $\begin{array}{l}\text { Log } \\
\quad \text { likelihood }\end{array}$ & 135.94 & & 66.09 & \\
\hline $\mathrm{AIC}$ & -1.599 & & -0.752 & \\
\hline SIC & -1.524 & & -0.667 & \\
\hline
\end{tabular}

Notes: $* *$ shows significance at $1 \%$ level. AIC, Akaike information criteria; SIC, Schwarz information criteria.

Otherwise, there is no herding, since $H_{m t}=0$ for all $t^{8}{ }^{8}$ After the inclusion of the exogenous variables, if $H_{m t}$ and $\varphi_{m}$ become insignificant, one concludes that changes in $\operatorname{Ln}\left[\operatorname{Std}_{c}\left(\beta_{\text {imt }}^{b}\right)\right]$ are explained by market movements rather than herding. The cross-section SDs of betas for each month and stocks for the BIST30 and the SNM are calculated by:

$$
\operatorname{Std}(\beta)_{t}=\sqrt{\frac{\sum_{i=1}^{a}\left(\text { beta }_{i t}-\overline{\text { beta }_{t}}\right)^{2}}{n-1}}
$$

where $t, i$ and $\overline{\text { beta }_{t}}$ represent the month, the firm and the cross-sectional average of all betas, respectively. The Jarque-Bera statistics indicate that the null of normality is not rejected for the $\ln \left[\operatorname{std}_{c}\left(\beta^{b}{ }_{i m t}\right)\right]$ for both indices.

\section{Results}

The maximum likelihood estimates of the parameters for the BIST30 and the SNM are reported in Table 2.

First, all coefficients of the base models for the BIST30 and the SNM are statistically significant. The parameters associated with herding $\sigma_{m \eta}$ and $\varphi_{m}$ (the herd persistent parameter) are highly significant both for the BIST30 and for the SNM. With control variables, however, the herd persistent parameter $\varphi_{m}$ and the variance of the signal error term for the BIST30 turned out not to be significant, while those of the SNM remained highly significant and roughly the same as those of the base model. Hence, the $\ln \left[\operatorname{std}_{c}\right.$ $\left.\left(\beta^{b}{ }_{i m t}\right)\right]$ of the BIST30 model seems to be explained by the two market movement variables and not by herding, whereas there is strong empirical support that the SNM investors/traders did behave with sentimental herding. Given that the AR(1) coefficient is 0.939 and all the other coefficients are still highly significant, sentimental herding by the SNM investors/traders was persistent and independent of market movements. This verifies the above hypothesis that it is the investors/traders' sentiment rather than market fundamentals that steers herd behaviour (Hwang and Salmon, 2004).

Figure 1 shows the line graphs of $h_{m t}=1-\exp \left(H_{m t}\right)$ for the BIST30 and the SNM. While the graph for the BIST30 follows the zero line, the herding path of the SNM investors/traders appears perceptible and with oscillations between 0.15 and -0.20 bounds, implying that herding has not been violent. This is also substantiated by the signal to noise ratio of 0.195 (see also Table 2).

The SNM herding occurs in three distinct stages. The first stage (2000-2004) shows three peaks and three attempts of adjustment to the fundamentals. The three attempts of adjustments of herding during this first stage (see Figure 1) are associated first with the end of the financial crisis of 2000-2001; second, with the inauguration of the new majority government in 2002 and third, with the beginning of the significant inflow of foreign capital in 2004, which spread a feeling of confidence in policies pursued.

The second stage (2005-2008) appears to be calm and smooth, when the markets were transparent and easy to predict (Demir et al., 2014). The investors/traders were finally convinced that governmental authorities were sincere in their implementation and use of sound monetary and fiscal policies as well as that of structural reforms.

The third stage (2008-2013) is characterized with a volatile adverse herding pattern $\left(h_{t}<0\right)$. Hwang and Salmon (2004) argue that, if there is herding, then there must be adverse herding for adjusting to the long-term equilibrium of the risk-return relationship from mispricing. Surprisingly in our model, adverse herding follows the no-herding period. Investors/traders of the SNM were unexpectedly shocked in the first quarter of 2008 by two serious events: the constitutional court action against the government and the mortgage crisis. While the BIST30 investors/traders were fully in line with the market, seeming to be aware of and prepared for the consequences of two negative events at the same time, the SNM investors/traders were in shock and confusion, likely because of their fear that the government in which they had trusted for the past several years could suddenly be dissolved and that foreign funds, which were fuelling the BIST since

\footnotetext{
${ }^{8}$ Higher order autoregressive processes were not found to be statistically significant.
} 


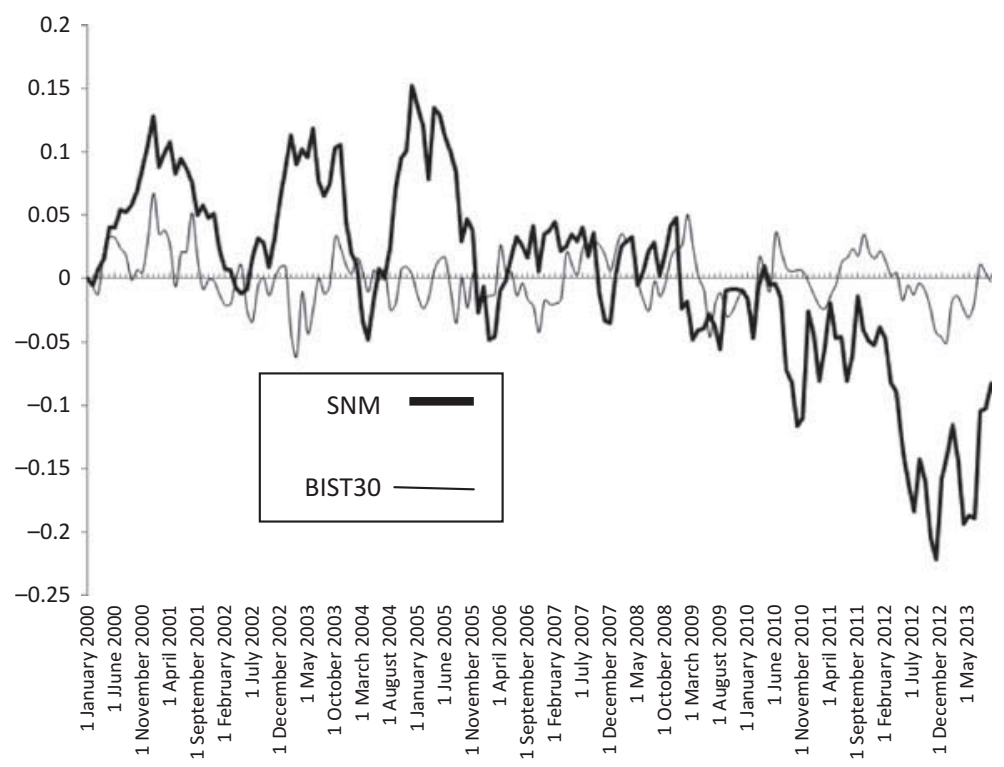

Fig. 1. Herding by second national market (SNM)

2004, could soon come to an end. Thus, we see an example of uninformed investors/traders sheltering themselves with the fundamental values of firms instead of following the market sentimentally.

\section{Conclusions}

This study investigates the existence of herding in BIST, between January of 2000 and September of 2013, by considering two important indices, which we assumed would behave differently: the BIST30 covering the largest firms with foreign portfolio investments and the SNM containing small- to medium-sized firms and firms delisted from the National Index. By using an AR(1) statespace model (Hwang and Salmon, 2004), we find no evidence of sentimental herding for investors/traders in the BIST30 but, in contrast, we find ample evidence of sentimental herding for the SNM investors/traders. Furthermore, the herding pattern of the SNM investors/ traders follows three distinct stages. The first stage of herding is explained by the financial crisis and lack of confidence towards the government (2000-2004), the second stage is a period of confidence with no herding (2005-2008) and the third stage (2009-2013) is a prolonged period of adverse herding, with conflicting signals received by investors/traders from shocking events, regarding the possibility of a government crisis as well as the mortgage crisis, both of which turn investors/traders back to usage of the long-term equilibrium risk-return relationship instead of sentimental herding. These findings are critical for emerging markets. First, herding revealed by these models may be a group-specific phenomenon rather than applicable to the whole market. Second, since herding leads to the mispricing of assets as well as to inefficiencies, authorities should minimize such herding, implementing different means for investors/traders, such as perhaps better access to information and/or training sessions for awareness.

\section{References}

Banerjee, A. (1992) A simple model of herd behavior, The Quarterly Journal of Economics, 107, 797-817. doi: $10.2307 / 2118364$

Bikchandani, S. and Sharma, S. (2001) Herd behaviour and financial markets, IMF Staff Papers, 47, 279-310.

Chang, E. C., Cheng, J. W. and Khorana, A. (2000) An examination of herd behavior in equity markets: an international perspective, Journal of Banking and Finance, 24, 1651-79. doi:10.1016/S0378-4266(99)00096-5

Christie, W. G. and Huang, R. D. (1995) Following the pied piper: do individual returns herd around the market?, Financial Analysts Journal, 51, 31-7. doi:10.2469/faj. v51.n4.1918

Demir, N. S., Mahmud, F. and Solakoglu, M. N. (2014, forthcoming) Sentiment and beta herding in Borsa Istanbul (BIST), in Risk Management Post Financial Crisis: A Period of Monetary Easing, Vol. 96, Batten, J. A. and Wagner, N. F. (Eds), Emerald.

Hwang, S. and Salmon, M. (2004) Market stress and herding, Journal of Empirical Finance, 11, 585-616. doi:10.1016/j. jempfin.2004.04.003

Lakonishok, J., Shleifer, A. and Vishny, R. (1992) The impact of institutional trading on stock prices, Journal of Financial Economics, 32, 23-43. doi:10.1016/0304-405X(92) 90023-Q

Wermers, R. (1999) Mutual fund herding and the impact on stock prices, The Journal of Finance, 54, 581-622. doi:10.1111/0022-1082.00118 